\title{
Children with rare diseases, is it true that they have an enhanced anesthesiological risk?
}

\author{
Maria Sammartino*, Fabio Sbaraglia, Francesco A Idone \\ From 71st Congress of the Italian Society of Pediatrics. Joint National Meeting SIP, SIMGePeD, Study Group \\ on Pediatric Ultrasound, SUP Study Group on Hypertension \\ Rome, Italy. 4-6 June 2015
}

The anesthesiological approach to rare diseases (RD) is particularly challenging for providers. The high number of pathologies and the scarcity of clinical reports impedes to arrange a pool of dedicated anaesthesiologists. When facing $\mathrm{RD}$, the risk linked to unaware malpractice is often due to lack of experience, mostly of urgent/emergent procedures [1].

It is probably impossible to know all relevant aspects in more than 8000 pathologies that affect approximately $6-8 \%$ of the population [2]. In order to reduce anesthesiological risk, it is mandatory to develop a systematic approach.

1. First and foremost, let's take advantage of previous experiences. There are specific search engines available online [http://www.orphananesthesia.eu; http://www. orpha.net; http://www.omim.org

], which briefly summarize the knowledge about RDs. Furthermore, for major pathologies there are national and international main centres providing medical counselling.

As a whole, we can attribute the anesthesiological risk to four cohorts.

Careful evaluation should be dedicated to current systemic impairments [3]. Children affected by cystic fibrosis need special care, due to specific organ failure. In some types of porphyrias it is mandatory to achieve a good control on pain, anxiety and nausea, because stressful events could trigger a severe crisis.

In some cases, pathological processes can affect pharmacodynamics causing abnormal responses to drugs, such as the enhancement of curarization in myasthenic patients, or a real adverse event like the risk of Malignant

\footnotetext{
* Correspondence: marinasammartino@libero.it

Department of Anesthesia and Intensive Care, Catholic University of Sacred
} Heart, Rome, Italy

Hyperthermia associated with Wolf-Hirschhorn Syndrome [4] or Arthrogryposis.

A third item to investigate is whether anesthetic drugs can interact with specific concurrent therapies. There are some suggestions that the previous therapy with eculizumab, a new monoclonal antibody for the treatment of paroxysmal nocturnal haemoglobinuria, predisposes to haemolytic crisis in occurrence of general anesthesia.

The last cohort, but the most frequent, concerns the difficult management of airways. Craniofacial malformations can represent a very big deal due to mandible hypoplasia such as Pierre Robin syndrome or Treacher-Collins syndrome; hemifacial microsomia such as Goldenhar syndrome; midface hypoplasia as Apert syndrome [5], Crouzon syndrome, Pfeiffer syndrome and macroglossia such as Hurler's syndrome, Hunter's syndrome, or weakness of atlanto-occipital joint such as Downs syndrome, EhlersDanlos syndrome type IV or osteogenesis imperfecta. Tracheal intubation should indeed be avoided in syndromes as epidermolysis bullosa to prevent severe tracheal lesions.

In conclusion, besides patients with a clear diagnosis, sometimes a simple pathology can hide unknown RDs [6]. For this reason the pre-anesthesiological evaluation is crucial, more than ever in syndromic children, to assess the risk before undergoing general anesthesia or sedation. This allows the best strategy to work safely to be put in place and to improve outcome.

\section{Published: 30 September 2015}

References

Knight AW, Senior TP: The common problem of rare disease in general practice. Med J Aust 2006, 17(185):82-83.

EURORDIS: What is a rare disease?, Accessed at http://www.eurordis.org/ about-rare-diseases. 
3. Tumolo M, Moscatelli A, Silvestri G: Anaesthetic management of a child with fibrodysplasia ossificans progressive. Br J Anaesth 2006,

97(5):701-703.

4. Sammartino M, Crea MA, Sbarra GM, Fiorenti M, Mascaro A: Absence of malignant hyperthermia in an infant with Wolf-Hirschhorn syndrome undergoing anesthesia for ophthalmic surgery. J Pediatr Ophthalmol Strabismus 1999, 36(1):42-43.

5. Sbaraglia F, Lorusso R, Garra R, Sammartino M: Usefulness of Airtraq in a 3-month-old child with Apert Syndrome. Paediatr Anaesth 2011, 21(9):984-985.

6. Sammartino M, Morelli Sbarra G, Ferro G, Chiusolo F, Garra R, Marzola M, et al: Pre-anesthesiological assessment in paediatric cataract surgery. Eur Rev Med Pharmacol Sci 2003, 7(1):27-31.

doi:10.1186/1824-7288-41-S2-A63

Cite this article as: Sammartino et al: Children with rare diseases, is it true that they have an enhanced anesthesiological risk? Italian Journal of Pediatrics 2015 41(Suppl 2):A63.

\section{Submit your next manuscript to BioMed Central} and take full advantage of:

- Convenient online submission

- Thorough peer review

- No space constraints or color figure charges

- Immediate publication on acceptance

- Inclusion in PubMed, CAS, Scopus and Google Scholar

- Research which is freely available for redistribution

Submit your manuscript at www.biomedcentral.com/submit
() Biomed Central 